\title{
KINH NGHIỆM ÁP DỤNG 5S TÙ THỰC TẾ TRƯờnG ĐẠI HỌC CÔNG NGHIỆP THÀNH PHỐ HỒ CHÍ MINH
}

\author{
BÙI THI HẢO \\ Khoa Lý luận Chính trị,Trường Đại học Công nghiệp Thành phố Hồ Chí Minh \\ buithihao@iuh.edu.vn
}

Tóm tắt: 5S (Seiri, Seiton, Seiso, Seiketsu, Shitsuke) là một trong ba nội dung của Dự án JICA-IUH (Dự án Phát triển nguồn nhân lực ngành hóa chất - công nghiệp nặng) được triển khai từ năm 2013 tại trường Đại học Công nghiệp Thành phố Hồ Chí Minh. Mục tiêu của $5 \mathrm{~S}$ là tạo ra môi trường làm việc sạch đẹp, gọn gàng ngăn nắp, khoa học, đem lại hiệu quả công việc mức độ cao. Trên cơ sở thực tiễn triển khai mô hình $5 \mathrm{~S}$ tại trường Đại học Công nghiệp Thành phố Hồ Chí Minh, bài viết làm rõ cơ sở lý thuyết, phân tích tính hiệu quả của quá trình triển khai $5 \mathrm{~S}$ tại trường, chắt lọc ý kiến từ các chuyên gia Nhật $\mathrm{Bản}$, từ đó rút ra năm bài học kinh nghiệm thực hiện $5 \mathrm{~S}$ đảm bảo môi trường làm việc hiện đại, chuyên nghiệp để vận dụng vào trường đại học giai đoạn hiện nay.

Từ khóa: Kinh nghiệm áp dụng mô hình $5 \mathrm{~S}, 5 \mathrm{~S}$ và mô hình Kosen-IUH.

\section{EXPERIENCE IN APPLICATION OF 5S FROM REALITY OF HO CHI MINH CITY INDUSTRY UNIVERSITY}

Summary: 5S (Seiri, Seiton, Seiso, Seiketsu, Shitsuke) is one of the key contents of the Project JICA-IUH (The Project for Human Resources Development for Heavy-chemical Industry), which was initiated at the Industrial University of Ho Chi Minh City in 2013. The goal of 5S is to create an organized and scientific working environment, to bring high levels of work efficiency. Based on the practical implementation of $5 \mathrm{~S}$ model at Industrial University of Ho Chi Minh City, the article clarifies the theoretical basis, analyzes the effectiveness of the $5 \mathrm{~S}$ implementation process at the university, and refines opinions from Japanese experts, from which draws five lessons of experience in $5 \mathrm{~S}$ implementation to ensure a modern and professional working environment to apply to the university in the current period.

Key words: Experience in applying 5S, 5S and Kosen-IUH models.

\section{1. ĐĂT VẤN ĐỀ}

Môi trường làm việc là nhân tố quan trọng, ảnh hưởng đến năng xuất và chất lượng công việc. Môi trường làm việc chuyên nghiệp, hiện đại, có nhiều yếu tố khuyến khích, thúc đẩy năng lực thì người lao động càng có thêm động lực phấn đấu cho công việc. Môi trường làm việc bao gồm nhiều yếu tố như cảnh quan, không gian xung quanh, mối quan hệ giữa cá nhân với cá nhân, giữa cá nhân với tập thể, cơ hội thăng tiến trong sự nghiệp, chế độ đãi ngộ... Để có môi trường làm việc hiệu quả thì trước hêt không gian xung quanh, đồ dùng, dụng cụ, hồ sơ, giấy tờ phải được sắp xếp gọn gàng, sạch sẽ, khoa học. Với tiêu chí sàng loc, sắp xếp, sạch sẽ, săn sóc, sã̃n sàng, $5 \mathrm{~S}$ giúp phân loại, bố trí, sắp đặt mọi thứ ngăn nắp, giữ gìn vệ sinh, đảm bảo môi trường, mỹ quan, thuận tiện cho công việc. Đây là yếu tố thiết thực của môi trường làm việc hiện đại, chuyên nghiệp ở các trường đại học.

$5 \mathrm{~S}$ có vai trò quan trọng trong môi trường làm việc nên nhận được sự quan tâm của các chuyên gia, các nhà nghiên cứu và sự hưởng ứng của các doạnh nghiệp, tổ chức. Có những nghiên cứu mang tính chuyên sâu như nghiên cứu của nhóm tác giả Lê Minh Tâm, Shibata Noriaki (2007), "5S trong công ty của bạn"; Phan Chí Anh (2008), "Thực hành 5S - Nền tảng cải tiến năng suất" hay "Thực trạng áp dụng $5 \mathrm{~S}$ tại các doanh nghiệp sản xuất công nghiệp nhỏ và vừa trên địa bàn thành phố Hà Nội” của nhóm tác giả Đại học kinh tế thuộc Đại học quốc gia Hà Nội. Theo đó, các tác giả cho rằng xu thế áp dụng $5 \mathrm{~S}$ là tất yếu khách quan và chỉ ra ưu điểm vượt trội của việc áp dụng $5 \mathrm{~S}$ vào các doanh nghiệp, tổ chức. Tuy nhiên, triết lý giáo dục của trường đại học hướng tới nâng cao chất lượng, phát triển bền vững, hội nhập quốc tế. Các chuẩn đầu ra, chương trình, phương pháp dạy học và quản lý tiếp cận với giáo dục khu vực, thế giới. Sinh viên ra trường thích ứng với cuộc cách mạng khoa học công nghệ 4.0, xây dựng ý thức kỉ luật, tinh thần tập thể, phát huy tiềm năng, sự cống hiến của mọi cá nhân, đáp ứng yêu cầu nguồn nhân lực cho xã hội. Do đó, các 
nghiên cứu trên chưa xuất phát từ thực tiễn một trường đại học cụ thể để nghiên cứu, từ đó thấy được những thuận lợi, khó khăn thách thức cần vượt qua làm bài học kinh nghiệm áp dụng mô hình $5 \mathrm{~S}$ trong các trường đại học giai đoạn hện nay. Nhận thức được vấn đề trên, tác giả nhận thấy việc thực hiện mô hình $5 \mathrm{~S}$ theo tiêu chuẩn Nhật Bản sẽ góp phần quan trọng để trường đại học đạt được mục tiêu giáo dục, đào tạo, do đó, tác giả lựa chọn nghiên cứu thực tế áp dụng $5 \mathrm{~S}$ tại trường Đại học Công nghiệp Thành phố Hồ Chí Minh làm bài học kinh nghiệm áp dụng vào môi trường Đại học để trường đại học trở thành môi trường làm việc chuyên nghiệp, hiện đại, hiệu quả giai đoạn hiện nay.

\section{NỘI DUNG, KẾT QUẢ THỰC HIỆn 5S TẠI TRƯờnG ĐẠI HỌC CÔNG NGHIỆP THÀNH PHỐ HỒ CHÍ MINH}

2.1. Nội dung và quá trình thực hiện $5 \mathrm{~S}$ ở trường Đại học Công nghiệp Thành phố Hồ Chí Minh 2.1.1. Nội dung $5 S$

5S là viết tắt của Seiri - Sàng lọc, Seiton - Sắp xếp, Seiso - Sạch sẽ, Seiketsu - Săn sóc, Shitsuke - Sã̃n sàng là một trong 03 nội dung chính của Mô hình đào tạo Kosen (5S, đổi mới phương pháp giảng dạy theo mô hình PBL (Problem-base-learning/Project-base-learning, hoạt động kết nối doanh nghiệp). Cùng với giảng dạy theo phương pháp $\mathrm{PBL}$, kết nối doanh nghiệp thì $5 \mathrm{~S}$ là phương pháp quản lý sắp xếp nơi làm việc, học tập một cách khoa học, tạo môi trường làm việc thân thiện, thoải mái nhằm nâng cao hiệu quả công việc, từ đó nâng cao hình ảnh cá nhân, hình ảnh của tổ chức với đối tác và xã hội

$5 \mathrm{~S}$ có ý nghĩa áp dụng đối với dụng cụ, công cụ, thiết bị, quản lý hồ sơ giấy tờ, các thủ tục hành chính và được cụ thể hóa bởi 5 nội dung. Hoạt động $5 \mathrm{~S}$ cần sự tham gia của cả tập thể, sự quyết tâm của lãnh đạo, sự tự giác của cá nhân, phương pháp thực hiện, sự phối hợp giữa các đơn vị trong tổ chức và cố vấn của các chuyên gia, đặc biệt là các chuyên gia đến từ Nhật Bản - cái nôi của $5 \mathrm{~S}$.

Seiri (Sàng lọc): Sàng lọc đồ vật, vật dụng, trang thiết bị, máy móc, hồ sơ, giấy tờ, tài liệu theo 4 tiêu chí: Đang sử dụng; thường xuyên sử dụng; ít khi sử dụng và không sử dụng.

Seiton (Sắp xếp): Phân loại đồ vật, hồ sơ, giấy tờ, tài liệu thành 4 nhóm và áp dụng các giải pháp:

- Nhóm đang sử dụng: Đặt ở ngay trước mặt, trên bàn

- Nhóm thường xuyên sử dụng: Đặt trong tầm tay sử dụng

- Nhóm ít khi sử dụng: Đặt kế bên, bên cạnh

- Nhóm không sử dụng: Đưa vào kho hoặc hủy bỏ.

Nên sử dụng tối đa không gian trong các tủ. Đồ vật, hồ sơ, giấy tờ phải được sắp xếp hợp lý, dễ sử dụng, đảm bảo tính thẩm mỹ. Đối với hồ sơ, giấy tờ, tài liệu vào loại mật hay hạn chế tiếp cận thì phải có khu vực riêng và thiết lập chế độ bảo mật. Không đặt hồ sơ, giấy tờ, tài liệu gây cản trở lối đi hay lối thoát hiểm. Hạn chế để các đồ vật ra ngoài tủ, không để các đồ vật có kích thước hay trọng lượng lớn trên cao đề phòng rơi vào người nguy hiểm.

Seiso (Sạch sẽ): Quét dọn, lau chùi có tính hệ thống, đồng bộ các đồ vật, vật dụng, trang thiết bị, máy móc, hồ sơ, giấy tờ, tài liệu. Đối với những vật dụng, trang thiết bị, hồ sơ, giấy tờ, tài liệu đặc biệt có thể yêu cầu quy trình hay chất liệu làm sạch riêng.

Sạch sẽ giúp đảm bảo môi trường làm việc có lợi cho sức khỏe. Hồ sơ, giấy tờ, tài liệu không bị hư hại do ẩm mốc, bụi bẩn, dính, rách... cản trở công việc. Sạch sẽ còn giúp tạo ra sự ngăn nắp, cơ hội tìm lại đồ vật thất lạc, tăng cường tinh thần đoàn kết khi công tác được thực hiện một cách có tổ chức.

Seiketsu (Săn sóc): Ban hành quy định có tính nguyên tắc, đảm bảo công tác săn sóc được thực hiện định kì, có sự kiểm soát từ người quản lý. Thường xuyên quan tâm, nhắc nhở mọi người thực hiện săn sóc đồ vật, vật dụng, trang thiết bị, máy móc, hồ sơ, giấy tờ, tài liệu của cá nhân, tập thể thường xuyên và liên tục. Tuyên truyền ý thức tiết kiệm, bảo vệ môi trường, tái chế, tái sử dụng, không làm ảnh hưởng đến chức năng, nhiệm vụ của tổ chức.

Shitsuke (Sã̃n sàng): Duy trì đồ vật, hồ sơ, giấy tờ, tài liệu gọn gàng, ngăn nắp, sạch sẽ. Chia sẻ những thành quả, kinh nghiệm và tìm kiếm giải pháp nhằm cải thiện kết quả đạt được. Giai đoạn đầu các cá nhân, tập thể nghiêm túc thực hiện theo quy định của tổ chức, giai đoạn sau trở thành thói quen, ý thức tự nguyện, tự giác. Mỗi cá nhân, tập thể chú ý chia sẻ kinh nghiệm với các cá nhân và đơn vị khác.

\subsubsection{Quá trình thục hiện 5S tại trưòng Đại học Công nghiệp Thành phố Hồ Chí Minh}

Chương trình $5 \mathrm{~S}$ được thực hiện từ cuối năm 2013 bởi hai khoa là Công nghệ Hóa và Công nghệ Cơ khí tại trường Đại học Công nghiệp Thành phố Hồ Chí Minh. Nhà trường xác định, giai đoạn đầu hoạt động $5 \mathrm{~S}$ sẽ 
tập trung vào các đơn vị đào tạo thuộc khối kỹ thuật. Sau 5 năm thực hiện và thu được kết quả tốt, $5 \mathrm{~S}$ được triển khai mở rộng sang các đơn vị đào tạo khối kinh tế - luật - xã hội và các phòng ban chức năng. Khi Dự án JICA-IUH gần kết thúc nhà trường tiếp tục triển khai Dự án JICA-IUH Mở rộng. Đến nay, sau 7 năm duy trì và phát triển $5 \mathrm{~S}$ đã tạo ra nề nếp, trở thành niềm tự hào của nhà trường. Quá trình thực hiện $5 \mathrm{~S}$ các vật dụng đã được sàng lọc, không còn đồ bám bụi, tài liệu được mã hóa, sắp xếp gọn gàng. Phòng làm việc, phòng học, phòng thí nghiệm, khu vực kho, xưởng, hành lang, nhà vệ sinh, sân trường... được bố trí khoa học, sạch sẽ. Cán bộ, nhân viên, giảng viên, sinh viên trong toàn trường đều có ý thức giữ gìn và thực hiện $5 \mathrm{~S}$. Hoạt động $5 \mathrm{~S}$ trở thành nét nổi bật, niềm tự hào và là điểm mạnh của nhà trường trong quá trình tham gia kiểm định chất lượng giáo dục.

Với mục tiêu sàng lọc, phân loại đồ vật, hồ sơ, giấy tờ, tài liệu, sử dụng tối đa không gian trong môi trường làm việc chuyên nghiệp, đảm bảo hồ sơ, giấy tờ, đồ vật được sắp xếp hợp lý, dễ sử dụng, có tính thẩm mỹ sẽ đem lại sức khỏe cho người lao động, tăng tính hiệu quả và tinh thần đoàn kết trong công việc. Bên cạnh đó còn xây dựng được ý thức tự nguyện, tự giác trong thực hiện nội quy, quy định của nhà trường. Đến nay, tất cả các đơn vị trong toàn trường đều vui vẻ, tích cực tham gia thực hiện $5 \mathrm{~S}$. $5 \mathrm{~S}$ trở thành nề nếp, một nét văn hóa tốt đẹp của trường Đại học Công nghiệp Thành Phố Hồ Chí Minh.

Nội dung, phương pháp thực hiện 5S được cập nhật liên tục, vòng lặp PDCA (P - Plan: Lập kế hoạch hành động chi tiết, xây dựng mục tiêu cụ thể, thời gian biểu thực hiện, phân công trách nhiệm, công việc; $\mathrm{D}$ Do: Triển khai hoạt động đúng kế hoạch đề ra với nguồn lực và nguồn tài nguyên; $\mathrm{C}$ - Check: Kiểm tra hoạt động thực hiện và đánh giá kết quả so với kế hoạch, mục tiêu đặt ra; $\mathrm{A}$ - Atc: Điều chỉnh hoạt động đúng kể hoạch, đưa ra hướng đi mới cho nội dung kế hoạch tiếp theo) được áp dụng xuyên suốt. Không có chỗ cho lã̃nh đạo hay nhân viên với các cẩu trả lời không biết hay không rõ vật dụng, tài liệu, máy móc thiết bị nơi làm việc.

\subsection{Kết quả thực hiện $5 \mathrm{~S}$ tại trường Đại học Công nghiệp Thành phố Hồ Chí Minh \\ 2.2.1. Nhũng ưu điểm đã đạt đự̂c}

5S tại trường Đại học Công nghiệp Thành phố Hồ Chí Minh đã trở thành nề nếp. Năm 2018, trường có kế hoạch kiểm tra $5 \mathrm{~S}$ tại 09 đơn vị thì 7/9 đơn vị trong toàn trường đã lập Kế hoạch thực hiện $5 \mathrm{~S}$ theo mẫu chung của Nhà trường, trong đó có phân bổ thời gian thực hiện cho các tiêu chí, phân công trực cho các cá nhân cụ thể. Có 6/9 đơn vị lập hồ sơ, có bảng Kaizen công khai trên góc $5 \mathrm{~S}$ của đơn vị, có hồ sơ minh chứng. Hầu hết các đơn vị đã nhận thức được ý nghĩa của việc thực hiện $5 \mathrm{~S}$ nên việc lưu trữ, sắp xếp hồ sơ và giữ gìn vệ sinh tại nơi làm việc rất tốt, do đó, với cùng các tiêu chí đánh giá nhưng kết quả điểm số kiểm tra 5S năm 2019 cao hơn năm 2018.

Bảng so sánh kết quả thực hiện $5 S$ năm 2018 và năm 2019

\begin{tabular}{|c|c|c|c|c|l|c|c|c|}
\hline \multirow{2}{*}{ TT } & \multicolumn{4}{|c|}{ NĂM 2018} & \multicolumn{4}{|c|}{ NĂM 2019} \\
\cline { 2 - 9 } & Đơn vị & Điểm & $\begin{array}{c}\text { Xếp } \\
\text { loại }\end{array}$ & $\begin{array}{c}\text { Xếp } \\
\text { thứ }\end{array}$ & \multicolumn{1}{|c|}{ Đơn vị } & Điểm & Xếp loại & Xếp thứ \\
\hline 1 & Thư viện & 94,7 & Rất tốt & 1 & $\begin{array}{l}\text { Khoa Kế toán - Kiểm } \\
\text { toán }\end{array}$ & 95 & Rất tốt & 1 \\
\hline 2 & Khoa Luật & 94,5 & Rất tốt & 2 & Khoa Ngoại ngữ & 95 & Rất tốt & 2 \\
\hline 3 & P. Đào tạo & 91 & Rất tốt & 3 & $\begin{array}{l}\text { Phòng Tổ chức - } \\
\text { Hành chính }\end{array}$ & 94 & Rất tốt & 3 \\
\hline 4 & P. Dịch vụ & 88 & Tốt & 4 & $\begin{array}{l}\text { Khoa Quản trị kinh } \\
\text { doanh }\end{array}$ & 94 & Rất tốt & 3 \\
\hline 5 & TT. GDQP & 87 & Tốt & 5 & Trung tâm Thư viện & 92 & Rất tốt & 4 \\
\hline 6 & $\begin{array}{l}\text { Khoa May } \\
\text { Thời trang }\end{array}$ & 84 & Tốt & 6 & $\begin{array}{l}\text { Phòng KT \& ĐBCL } \\
\text { Rấn tốt }\end{array}$ & 4 \\
\hline 7 & $\begin{array}{l}\text { P. QLKH } \\
\text { và HTQT }\end{array}$ & 84 & Tốt & 7 & $\begin{array}{l}\text { Phòng Tài chính - Kế } \\
\text { toán }\end{array}$ & 91 & Rất tốt & 5 \\
\hline 8 & $\begin{array}{l}\text { Khoa } \\
\text { Nhiệt lạnh }\end{array}$ & 82,3 & Tốt & 8 & $\begin{array}{l}\text { Phòng Kế hoạch - } \\
\text { Đầu tư }\end{array}$ & 90 & Rất tốt & 6 \\
\hline
\end{tabular}




\begin{tabular}{|c|l|c|c|c|c|c|c|c|}
\hline 9 & $\begin{array}{l}\text { Khoa TC- } \\
\text { NH }\end{array}$ & 73,3 & Khá & 9 & VP Đoàn Thanh niên & 90 & Rất tốt & 6 \\
\hline
\end{tabular}

Bảng so sánh kết quả thực hiện 5S năm 2018 và năm 2019 tại các đơn vị trong trường Đại học Công nghiệp Thành phố Hồ Chí Minh cho thấy, mặc dù các tiêu chí đánh giá như nhau nhưng qua quá trình triển khai thực tế tại các đơn vị thì ý thức thực hiện $5 \mathrm{~S}$ ngày càng cao dẫn đến điểm số cũng cao hơn trước. Điều đó cho thấy việc thực hiện $5 \mathrm{~S}$ tại trường Đại học Công nghiệp Thành phố Hồ Chí Minh đúng hướng và ý thức của cán bộ, giảng viên, sinh viên toàn trường về thực hiện $5 \mathrm{~S}$ ngày một nâng cao.

Bên cạnh đó, việc thực hiện $5 \mathrm{~S}$ cũng bài bản và có kế hoạch rõ ràng thồng qua bảng $5 \mathrm{~S}$ được treo công khai trong các đơn vị, do đó, các hoạt động $5 \mathrm{~S}$ được chuẩn hóa cả về lý thuyêt lẫn thực tế nên công tác $5 \mathrm{~S}$ ngày một hiệu quả.

Bảng Lịch công tác các đơn vị trong trường trước khi thực hiện $5 \mathrm{~S}$
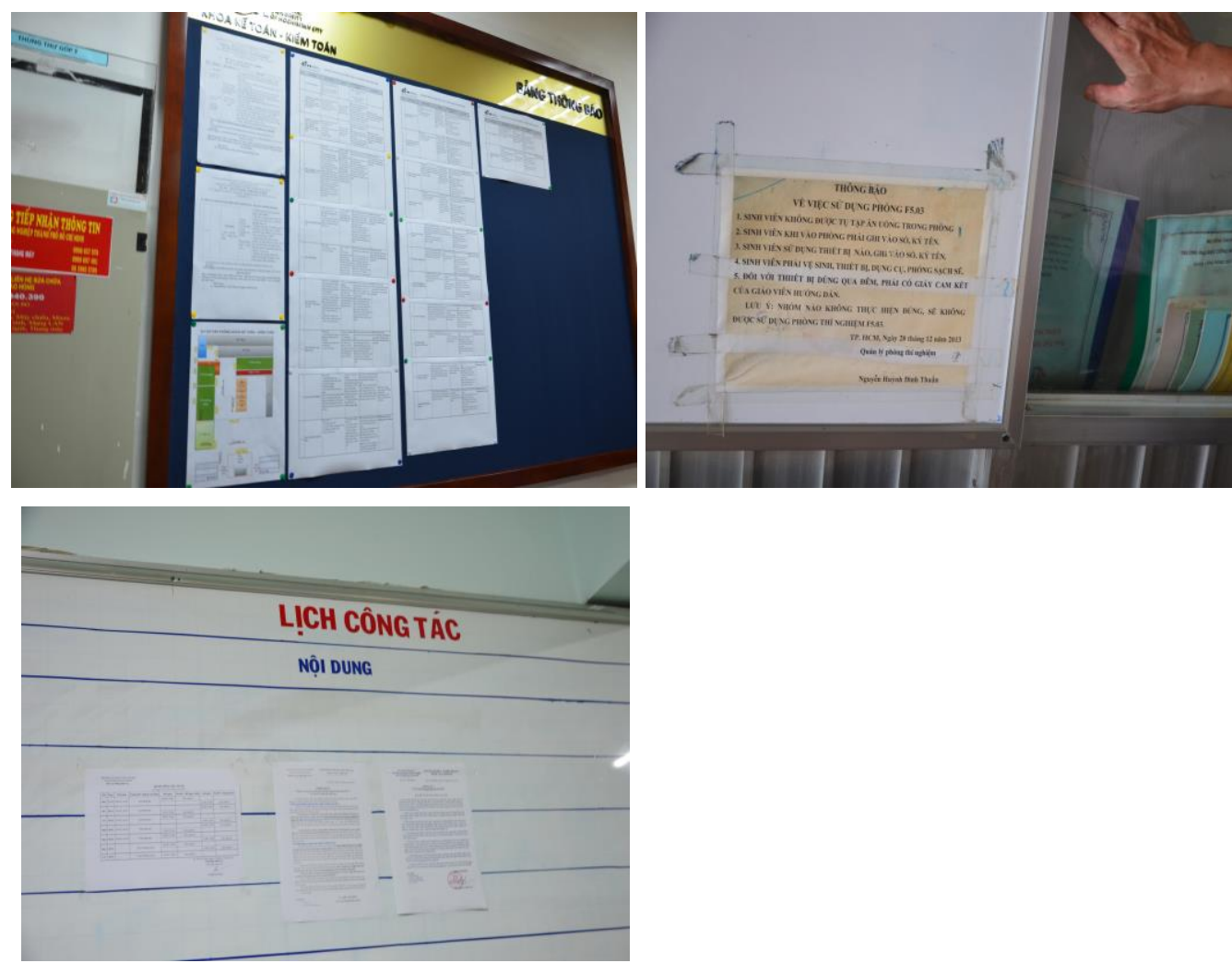

Bảng Lịch công tác các đơn vị trong trường sau khi thực hiện $5 \mathrm{~S}$ 

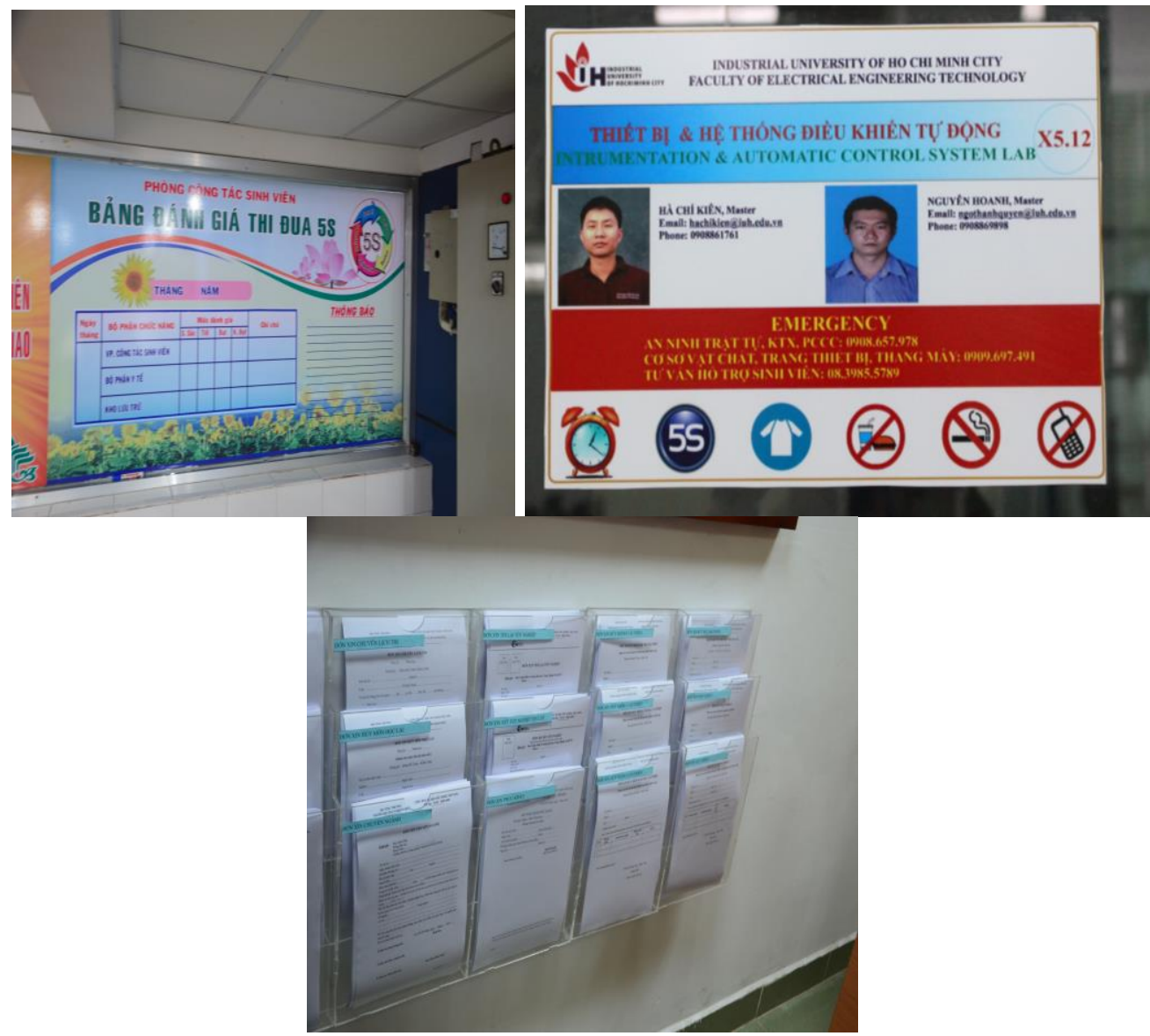

Như vậy, quá trình thực hiện $5 \mathrm{~S}$ đã đem lại những kết quả tích cực. Các bảng biểu được sắp xếp gọn gàng khoa học. Môi trường làm việc sạch sẽ, đẹp mắt, việc tra cứu, tìm kiếm tài liệu thuận lợi hơn trước rất nhiều.

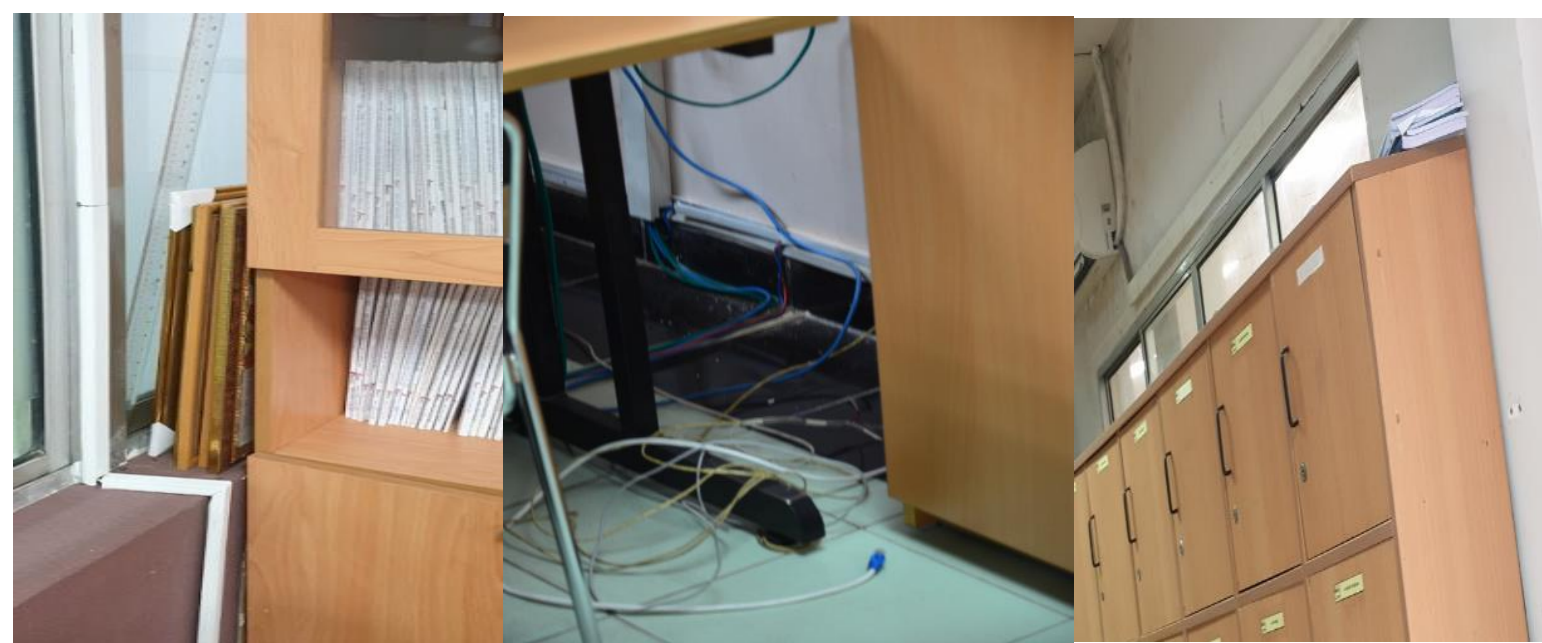




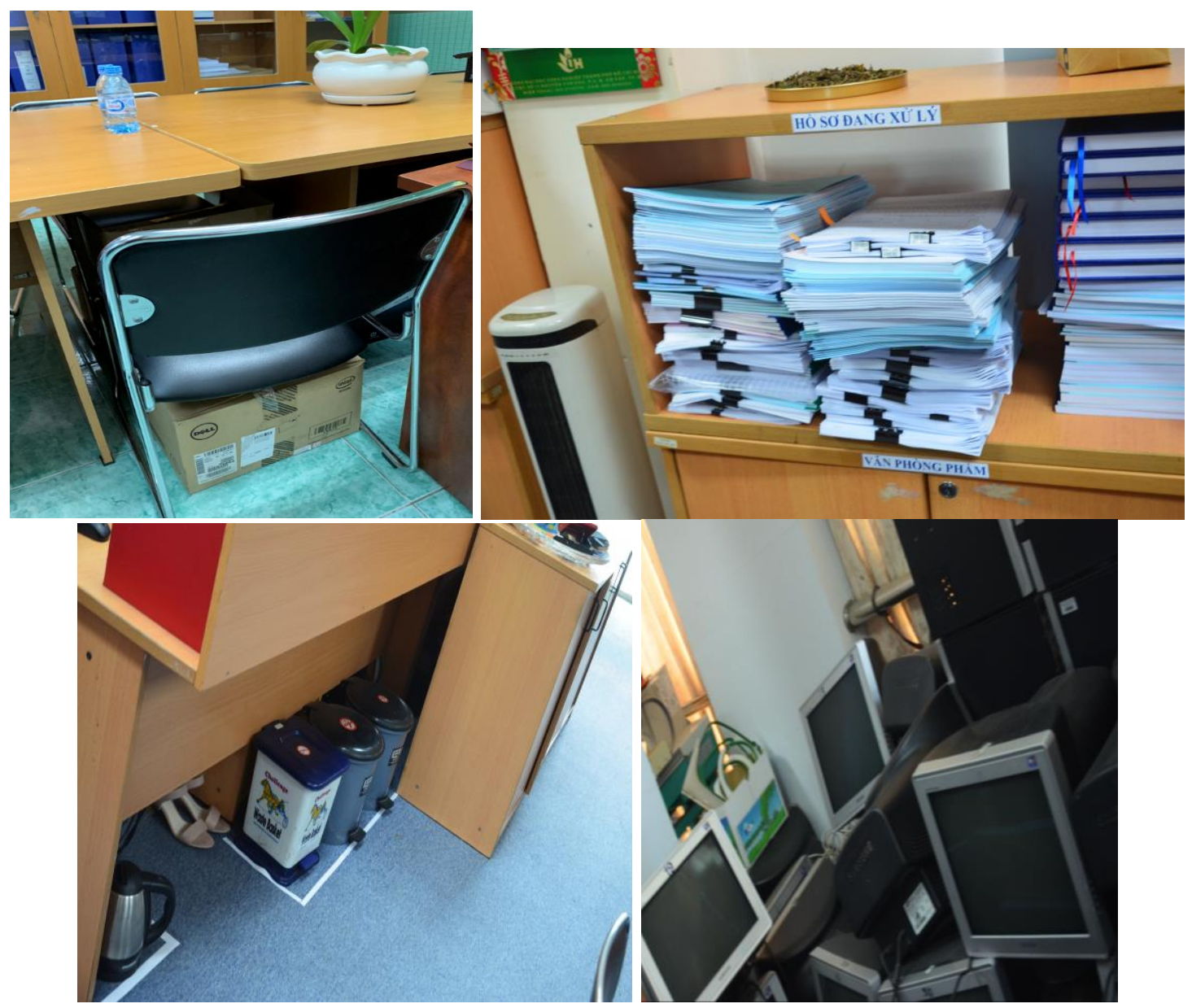

Hình ảnh tiêu biểu của một số đơn vị trong trường trước khi thụ̣c hiện $5 \mathrm{~S}$

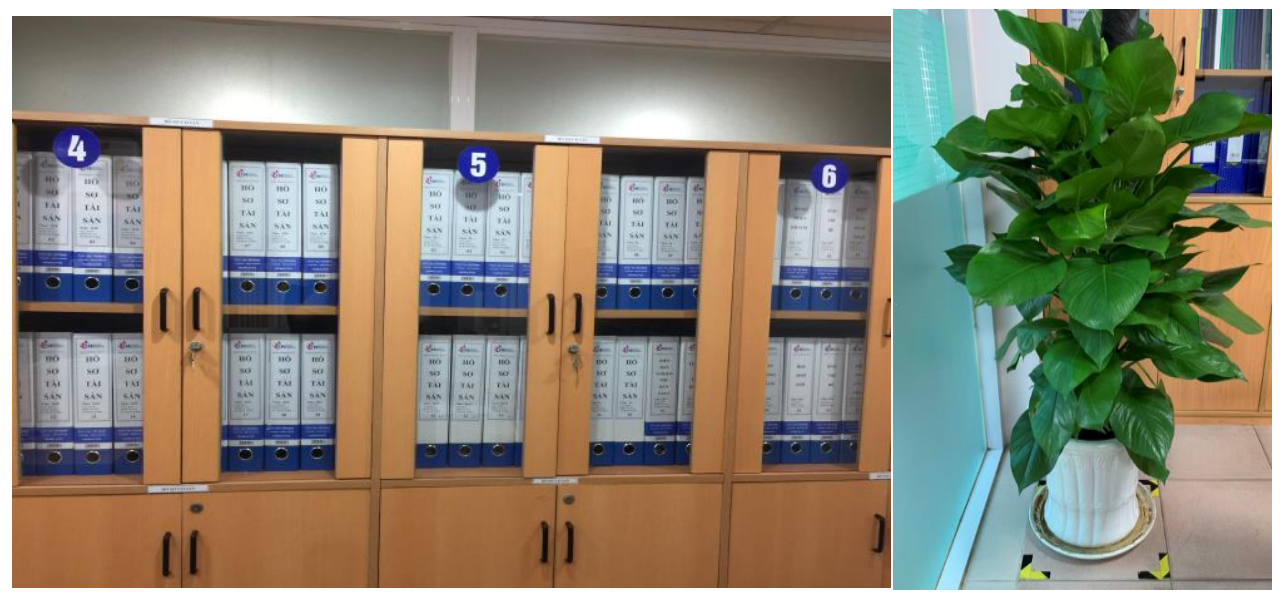




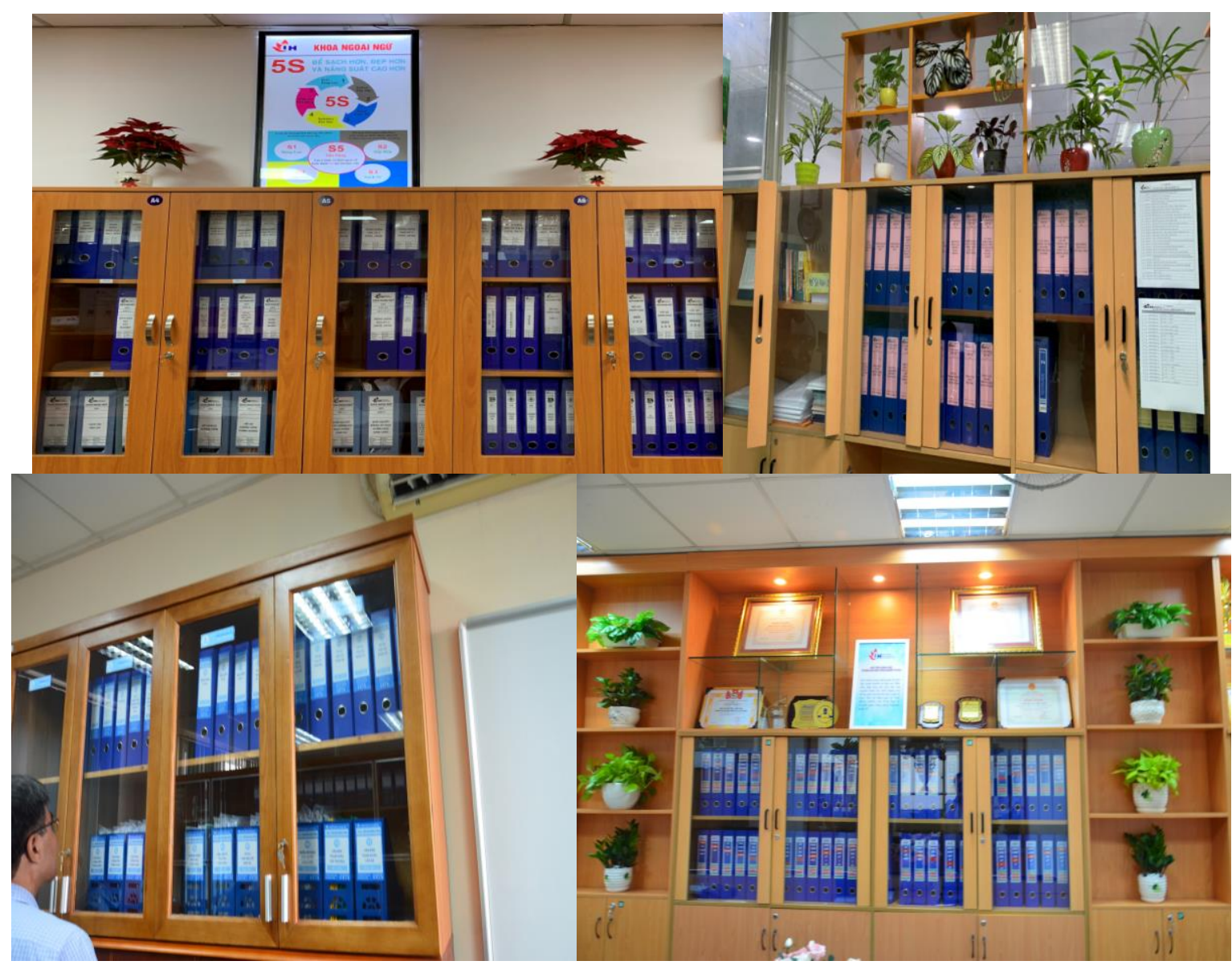

Hình ảnh tiêu biểu của một số đơn vị trong trường sau khi thụ̣c hiện $5 \mathrm{~S}$

Bên cạnh việc sắp xếp, kiểm tra, đánh giá các năm của nhà trường thì trong hoạch định cho các năm tiếp theo, các chuyên gia đều tham khảo ý kiến của lãnh đạo nhà trường, thảo luận các nội dung chi tiết để đáp ứng được yêu cầu của đơn vị. Giai đoạn này tiêu tốn khá nhiều thời gian. Các chuyên gia Nhật Bản giải thích về triết lý, khái niệm và ý nghĩa các nội dung $5 \mathrm{~S}$ trong thực tế. Sau khi được các bên thông qua sẽ được triển khai thực hiện. Nhà trường ban hành các văn bản, quyết định theo kế hoạch. Giai đoạn triển khai thực hiện là giai đoạn chính và chiếm phần lớn thời gian $5 \mathrm{~S}$. Đây cũng là giai đoạn phát sinh nhiều vấn đề nhất, phản ánh thực tế áp dụng $5 \mathrm{~S}$ và các phản hồi từ các đơn vị, cá nhân tham gia. Tuy nhiên, những khác biệt về lý thuyết và thực tế áp dụng $5 \mathrm{~S}$ được thể hiện thông qua giai đoạn kiểm tra - đánh giá. Bên cạnh việc nhà trường thường xuyên tổ chức các đợt kiểm tra, đánh giá nội bộ thì có hai đợt kiểm tra toàn diện (giữa kì và cuối kì) được thực hiện bởi đoàn đánh giá Nhật Bản. Các giảng viên, chuyền gia đại diện JICA, lãnh đạo nhà trường cùng tham gia đánh giá. Các kết luận kiểm tra - đánh giá được lưu lại để khắc phục trong thời gian tới.

\subsubsection{Một số tồn tại}

Thời gian qua, $5 \mathrm{~S}$ được xem là hoạt động đáng tự hào của trường Đại học Công nghiệp Thành phố Hồ Chí Minh, tuy nhiên, tại một số đơn vị hoạt động $5 \mathrm{~S}$ chưa được thực hiện thường xuyên, diễn ra tạm bợ, đối phó. Có đơn vị còn chưa ban hành kế hoạch cụ thể, hoặc có nhưng để trong tủ hoặc trong máy tính, khi đoàn kiểm tra đến mới in ra. Bảng phân công công việc không được dán công khai để cùng thực hiện. Còn tình trạng này là do một số cán bộ, nhân viên, giảng viên, sinh viên chưa nhận thức đầy đủ các nội dung $5 \mathrm{~S}$. Một số người còn cho rằng $5 \mathrm{~S}$ là công việc hành chính, giấy tờ nên việc phân công thực hiện cũng chỉ trên giấy chứ chưa có minh chứng, chưa biến $5 \mathrm{~S}$ thành hoạt động mang tính chất tự giác. Đặc biệt, khu vực phòng thí nghiệm, xưởng thực hành chưa được duy trì tốt so với khu vực văn phòng.

Kết quả kiểm tra năm 2018, 2019 một số khoa chưa đạt chuẩn 5S hoặc đạt nhưng còn ở mức độ khá. Danh mục tra cứu hồ sơ, vật dụng chưa được dán dấu chỉ vị trí. Đồ dùng dư thừa chưa được sắp xếp gọn gàng mà 
vẫn đặt trên nóc tủ, kẽ tường, gầm bàn. Phòng thí nghiệm, xưởng thực hành còn tình trạng thiết bị điện, dây mạng chưa được bó lại gọn gàng, không vệ sinh sạch sẽ và để lại vị trí cũ sau khi sử dụng. $5 \mathrm{~S}$ không phải là thay mới vật dụng hoàn toàn, tuy nhiên sau nhiều năm thực hiện $5 \mathrm{~S}$ nhưng vẫn còn nhiều hành lang chung chưa thay thế các tấm lót, chưa sơn sửa tường các khu vực nhà $X$, chưa thay cửa kính cường lực và gia cố hành lang an toàn bên ngoài ở một số tầng, chưa thay thế đồng bộ hệ thống chiếu sáng bằng đèn Led...
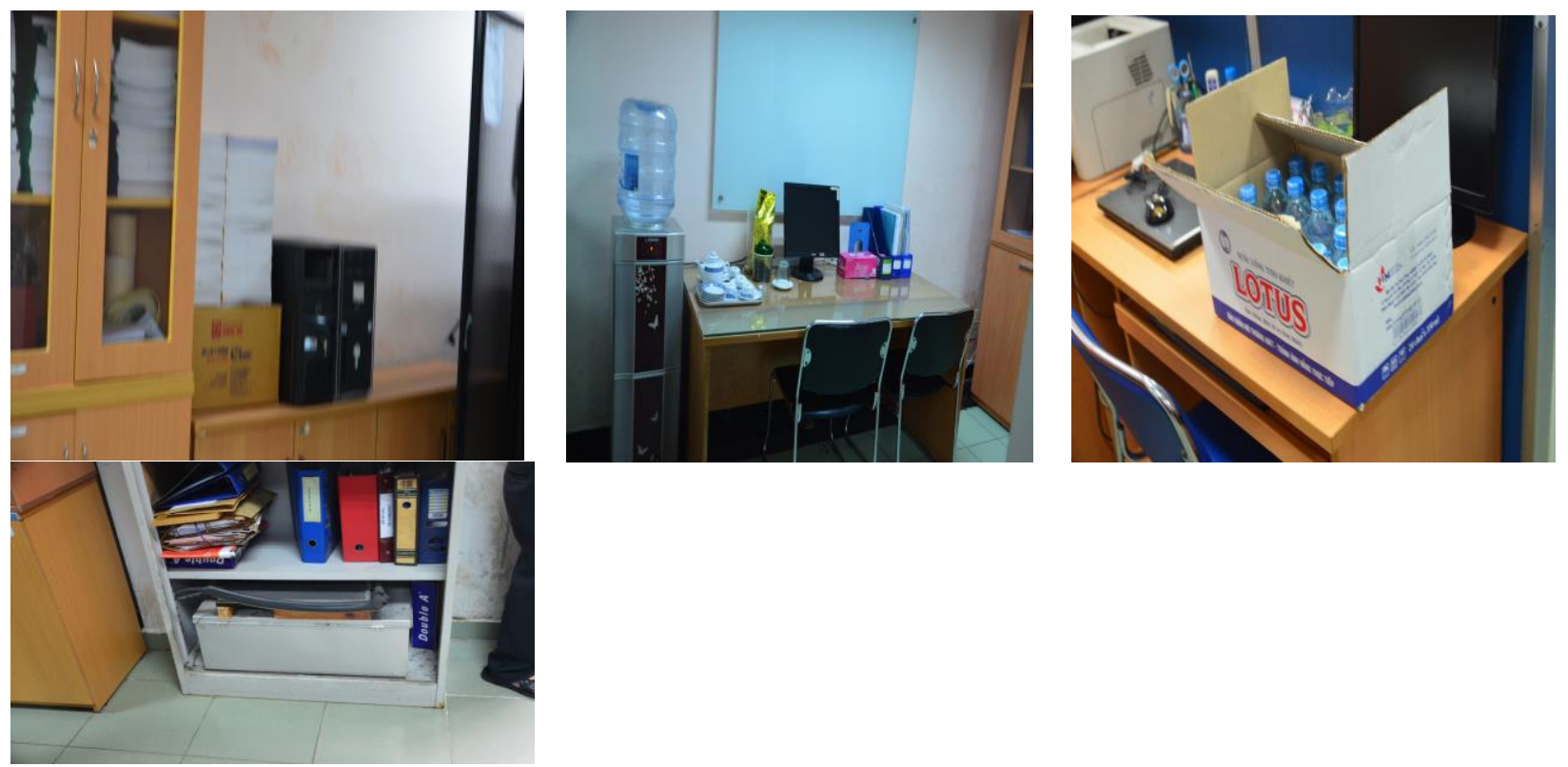

Hình ảnh một số đơn vị trong trường còn tình trạng để đồ không họ̣p lý

\subsection{Bài học kinh nghiệm áp dụng $5 \mathrm{~S}$ vào trường đại học}

\section{Đối với lãnh đạo quản lý}

Một là, lãnh đạo trong mỗi đơn vị luôn luôn là người khởi xướng, là đầu tàu trong quá trình hiện thực hóa các hoạt động của đơn vị, do đó, để hoạt động $5 \mathrm{~S}$ thành công thì lãnh đạo quản lý phải nhận thức đúng về $5 \mathrm{~S}$, tránh tình trạng qua loa, đối phó. Trong trường đại học, điều này đòi hỏi quyết tâm của lãnh đạo nhà trường. Lãnh đạo phải là người tiên phong thực hiện để nhân viên noi theo. Sự quyết tâm thể hiện bằng chế tài thông qua các quy định, quyết định hay động viên - khen thưởng. Tuy nhiên, sự nỗ lực của lãnh đạo sẽ không hiệu quả nếu không huy động được cả tập thể đơn vị cùng tham gia. Vai trò, ý thức tự giác của mỗi cá nhân tác động tích cực đến thành công trong thực hiện $5 \mathrm{~S}$. Mỗi cá nhân phải tự xác định, kiểm soát và chủ động thực hiện các hoạt động phân loại, sắp xếp, làm sạch vật dụng nơi mình làm việc. Hoạt động của mỗi cá nhân thể hiện tinh thần trách nhiệm với chính mình, với tập thể nơi mình công tác. Trong trường đại học, cá nhân không chỉ là cán bộ, viên chức, giảng viên mà còn là học viên, sinh viên cùng tham gia các hoạt động nghiên cứu, đào tạo trong nhà trường. Tuân thủ nội dung $5 \mathrm{~S}$ thể hiện ý thức tuân thủ kỉ cương, nề nếp của cá nhân đối với nhà trường.

Hai là, thống nhất cách thức thực hiện giữa đơn vị với cá nhân trong nhà trường. Thực hiện $5 \mathrm{~S}$ đòi hỏi mỗi cá nhân, tập thể phải cương quyết loại bỏ những hành vi, lối suy nghĩ lạc hậu trước đây. Để thực hiện được điều này không dễ vì những thói quen tồn tại lâu và có sự đồng thuận của tập thể. Thực hiện $5 \mathrm{~S}$ sẽ giảm thiểu số lượng, thu hẹp vị trí sử dụng của những vật dụng quen thuộc đối với mọi người ở nơi làm việc. Cũng không dễ dàng khi yêu cầu mọi người chia sẻ không gian, vật dụng vốn dĩ được sử dụng riêng thành sử dụng chung. Tuy khó khăn trong triển khai nhưng $5 \mathrm{~S}$ không chấp nhận sự hiện diện của những vật dụng không cần thiết tại nơi làm việc. Do đó, song song với loại bỏ vật dụng không cần thiết thì dãn nhãn, ghi rõ công dụng, vị trí, vai trò của những vật dụng có ích trong công việc. Tính logic của vấn đề ở chỗ mỗi vật dụng nếu thường xuyên được sử dụng, được người dùng quan tâm thì chắc chắn sẽ sạch sẽ, gọn gàng, ngăn nắp, hiệu quả.

Ba là, thực hiện kiểm tra - đánh giá thường xuyên để ghi nhận, động viên, khuyến khích đối với cá nhân, đơn vị. Nhà trường nên thường xuyên thực hiện kiểm tra - đánh giá cách thức hoạt động, quản lý và kiểm 
soát đối với đơn vị nhằm phát hiện sự khác biệt giữa thực tế với kế hoạch ban đầu. Xác định chủ thể chịu trách nhiệm kèm cam kết, giải pháp khắc phục tồn tại. Hoạt động kiểm tra - đánh giá cần lập kế hoạch, bố trí nhân sự, lên lịch, chuẩn bị máy chụp hình, xây dựng các tiêu chí đánh giá riêng cho từng khu vực của nhà trường như văn phòng, các khoa, viện, các lớp học lý thuyết, phòng thí nghiệm, xưởng thực hành, khu vực công cộng... để các các nhân, đơn vị thực hiện.

\section{Đối với giảng viên, nhân viên và sinh viên}

Một là, giảng viên, nhân viên và sinh viên là những người trực tiếp, thường xuyên thực hiện 5 nội dung (Seiri - Sàng lọc, Seiton - Sắp xếp, Seiso - Sạch sẽ, Seiketsu - Săn sóc, Shitsuke - Sã̃n sàng), do đó, họ phải luôn bám sát các tiêu chí để thực hiện. Vị trí các nhóm đồ vật, tài liệu phải được sắp xếp theo chủng loại, được đánh dấu chỉ dẫn, dán nhãn thông tin để giảm thiểu thời gian tìm kiếm. Không có mẫu nhãn thông tin chung cho tất cả hồ sơ, giấy tờ, tài liệu nhưng tiêu chí phổ biến nhất là sắp xếp theo trình tự thời gian. Việc sắp xếp tài liệu theo thời gian giúp xác định chính xác tên, tình trạng hiện hữu, vị trí tối ưu của đồ vật và là bằng chứng minh họa cách thức quản lý khoa học của đơn vị.

Hai là, giảng viên, nhân viên và sinh viên phải luôn ý thức được ý nghĩa của việc thực hiện $5 \mathrm{~S}$, có tinh thần tự nguyện, tự giác, chủ động thực hiện $5 \mathrm{~S}$ theo quy định đã được nhà trường ban hành.

Theo các chuyên gia Nhật Bản, không có một bộ tiêu chuẩn riêng hoặc duy nhất nào được sử dụng để đánh giá kết quả thực hiện $5 \mathrm{~S}$, các câu hỏi được các chuyên gia hay dùng khi kiểm tra đánh giá là: "Thứ này cần thiết không?", "Thứ này đúng vị trí chưa?", "Thú này dùng hiệu quả chua?", "Vị trí để có phù hơp không? " "Ai là người sủ dụng?". Thực tế, những thói quen đã hình thành từ lâu và duy trì trong thời gian dài tạo ra thói trì trệ, ngại thay đổi nển cần kiên trì, quyết liệt trong thực hiện. Dù vậy, tránh tình trạng đề cao vai trò của $5 \mathrm{~S}$ ảnh hưởng nhiệm vụ hay công tác chính của nhà trường.

\section{KẾT LUẬN}

Việc thực hiện $5 \mathrm{~S}$, theo các chuyên gia Nhật Bản, không phải là điều gì quá cao siêu, quá khó khăn, quá phiền phức hay tốn kém. Những thành quả to lớn đạt được sau khi thực hiện $5 \mathrm{~S}$ đều bắt nguồn từ những thay đồi nhỏ nhất mang tính tích cực trong đó sự đóng góp của từng cá nhân là nhân tố quyết định đến thành công của tổ chức. Mục đích cuối cùng mà $5 \mathrm{~S}$ hướng tới không phải vì một danh hiệu hay một phần thưởng mà tạo ra môi trường làm việc được bố trí khoa học, có lợi cho sức khỏe, góp phần nâng cao năng suất lao động của mọi người trong tổ chức, điều này vô cùng có ý nghĩa đối với các trường đại học giai đoạn hiện nay. Quá trình triển khai thực hiện đòi hởi sự đồng tâm, nhất trí của toàn thể các thành viên trong tổ chức. Trong Dự án JICA-IUH thể hiện sự quyết tâm của Ban giám hiệu nhà trường, ý thức tự giác của toàn thể cán bộ, viên chức, giảng viên, học viên, sinh viên. Quá trình thực hiện cho thấy sự phối hợp chặt chẽ giữa các phòng ban chức năng, các khoa, viện, trung tâm, các cơ sở với chuyên gia Nhật Bản đến từ các trường Kosen và Cơ quan hợp tác quốc tế Nhật Bản (JICA). Cuối cùng, $5 \mathrm{~S}$ chỉ thực sự thành công và có ý nghĩa khi những kết quả tích cực của $5 \mathrm{~S}$ được duy trì ổn định, thường xuyên lâu dài, tạo nền móng vững chắc cho văn hóa trường đại học.

\section{TÀI LIỆU THAM KHẢO}

1. Phan Chí Anh, (2008), Thực hành $5 \mathrm{~S}$ - Nền tảng cải tiến năng suất, NXB Lao động, Hà Nội.

2. Hayashida,T. (2013-2017). Tài liệu 5S. Dự án JICA-IUH, Đại học Công nghiệp thành phố Hồ Chí Minh

3. Khoa Kế toán - Kiểm toán (2016). Báo cáo thực hiện 5S, Đại học Công nghiệp thành phố Hồ Chí Minh

4. Hayashida, T. (2017). Ý nghĩa mô hình đào tạo Kosen. Hội thảo về Mô hình Kosen tại Đại học Công nghiệp thành phố Hồ Chí Minh

5. Báo cáo kết quả kiểm tra chuyên môn và kiểm tra $5 \mathrm{~S}$ tại trường Đại học Công nghiệp Thành phố Hồ Chí Minh năm 2018; 2019

6. Dự án JICA-IUH (2017). Tài liệu tập huấn mô hình đào tạo Kosen (2013-2017). Đại học Công nghiệp thành phố Hồ Chí Minh

7. Khoa công nghệ Hóa học (2017). Báo cáo thường niên tiến độ thực hiện Dự án JICA-IUH, Đại học Công nghiệp thành phố Hồ Chí Minh 


\section{THÀNH PHỐ HỒ CHÍ MINH}

8. Khoa Công nghệ Cơ khí (2017). Báo cáo thường niên tiến độ thực hiện Dự án JICA-IUH, Đại học Công nghiệp thành phố Hồ Chí Minh

9. Trường Đại học Công nghiệp thành phố Hồ Chí Minh (2017). Tài liệu hội thảo về mô hình Kosen

10. Trường Đại học Công nghiệp TP.HCM. Hướng dẫn số 03/HD-ĐHCN (2018) về thực hiện 5S

11. Trường Đại học Công nghiệp TP.HCM. Trung tâm Công nghệ thông tin

12. Lê Minh Tâm, Shibata Noriaki: 5S trong công ty của bạn, Hà nội, Nhà xuất bản thế giới, 2007.

13. Ibaraki College (10/2017). Một số hình ảnh về trường Ibaraki College. Chuyến công tác 10/2017

14. Nguyễn Quang Vinh (2018). Lý thuyết và thực tế áp dụng mô hình 5S: Trường hợp Dự án JICA-IUH tại trường Đại học Công nghiệp thành Phố hồ Chí Minh. Tạp chí Khoa học và Công nghệ, Đại học Công nghiệp, số 34, tháng 4/2018.

Ngày nhận bài: 01/06/2020

Ngày chấp nhận đăng: 15/10/2020 